\title{
The effect of lymph node metastasis on overall survival and disease-free survival in vulvar cancer patients
}

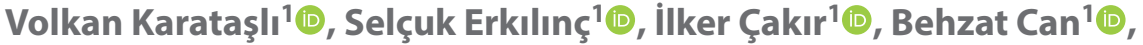 \\ Tuğba Karadeniz ${ }^{2}$, , Mehmet Gökçüi $^{1}$, Muzaffer Sancı ${ }^{1}(1)$ \\ ${ }^{1}$ Department of Gynecologic Oncology, University of Health Sciences Tepecik Education and Research Hospital, Izmir, Turkey \\ ${ }^{2}$ Department of Pathology, University of Health Sciences Tepecik Education and Research Hospital, Izmir, Turkey
}

\begin{abstract}
Objectives: To examine the effect of lymphadenectomy on survival in patients with squamous cell vulvar carcinoma.

Material and methods: Patients with squamous cell vulvar cancer who underwent surgery were retrospectively analyzed. All procedures were performed according to current recommendations/standard of treatment. The clinical and pathological features were examined. Sixty-eight patients were studied. The mean age was $64.7 \pm 10.9$ years. Twenty-three (33.8\%) patients had nodal metastasis. Most patients (60.3\%) were in stage IB. Adjuvant radiotherapy and chemo-radiotherapy were administered to $33.8 \%$ and $25 \%$ of the patients, respectively. The median follow-up time was 28.5 (4-183) months. Recurrence occurred in 18 (26.5\%) cases.

Results:There was no significant difference between node-positive and node-negative patients in terms of age, number of dissected lymph nodes and recurrence. Tumor diameter was significantly higher in the metastatic group. Age and surgical margin positivity were independent prognostic factors for overall survival (OS). Surgical margin positivity and lymph node metastasis had no effect on disease-free survival (DFS).

Conclusions: Our results showed that age and surgical margin positivity were independent prognostic factors for OS. Although surgical margin positivity increased the risk of recurrence in univariate analysis, it was not a significant factor affecting DFS. OS was significantly lower in patients with lymph node metastasis.
\end{abstract}

Key words: lymph node metastasis; prognostic factors; recurrence; squamous cell carcinoma; survival; vulvar cancer

Ginekologia Polska 2020; 91, 2: 62-67

\section{INTRODUCTION}

The incidence of vulvar cancer was reported to be 1.1 per 100.000 women in Poland [1]. Surgery is the mainstay treatment for early stage vulvar cancer [2-4]. However, definitive radiotherapy (RT) and chemo-radiotherapy (CRT) should be selected in patients with distant metastasis, locally advanced disease and older patients with medical comorbidities that are not fit for surgery [4]. Adjuvant treatment was found to increase disease-free survival (DFS) and overall survival (OS) in node-positive patients, but the information on the role of RT and CRT in node-negative patients is lacking [5].

The prognostic factors for vulvar cancer have been investigated in several studies [6-8]. Tumor invasion deeper than $2 \mathrm{~mm}$ was found to be a risk factor for local recur- rence [9]. Lymphovascular space involvement (LVSI) was also an independent risk factor for local recurrence [10]. Additionally, HPV-positive patients had less local recurrence than HPV-negative patients [11]. Conflicting data is present on the role of lymph node metastasis on recurrence in the literature $[9,12,13]$. Some authors reported that lymph node positivity was related with increased disease recurrence [12]. On the other hand, several studies have reported that lymph node metastasis had no effect on recurrence $[9,13]$. Surgical margin distance was also studied in several reports, and there is conflicting data on the role of the margin distance on recurrence $[14,15]$. There are also contradictory data on the effect of tumor size and grade on survival $[6,14]$. 


\section{Objectives}

The aim of this study was to investigate the effect of lymph node metastasis on survival in vulvar cancer patients.

\section{MATERIAL AND METHODS}

Patients with vulvar cancer who were treated between January 1995 and November 2018 were retrospectively analyzed. A total of 98 patients were encountered during the study period. Those with non-squamous histology $(n=13)$ and those treated with definitive RT or CRT $(n=17)$ were excluded. The data of the patients were obtained from patients' files and the hospital database. The collected data were tumor size, distance from midline (clitoris), association with urethra, anus and vagina, the status of inguinofemoral lymph nodes, Human Papilloma Virus (HPV) status, examination results of other parts of the lower genital tract, preoperative radiologic evaluation including posteroanterior $\mathrm{X}$-ray, computed tomography, magnetic resonance imaging and positron emission tomography. All gynecologic examinations were performed by gynecologic oncologists, and all pathologic slides were evaluated by experienced gynecopatologists. The preoperative findings of the patients were discussed in a multidisciplinary tumor board. The decision on optimal treatment was made according to age, performance status, diameter of tumor, status of lymph node metastasis and stage of the disease. The criteria for inguinofemoral lymphadenectomy (superficial and deep) was tumor diameter larger than $2 \mathrm{~cm}$. Sentinel lymphadenectomy was utilized to decrease the morbidity of full lymphadenectomy in unifocal tumors that were smaller than $4 \mathrm{~cm}$ and cases with clinically negative lymph nodes. Positive surgical margin was specified as continuity of the tumor at the surgical margin or tumor in the surgical margin below $8 \mathrm{~mm}$. Surgical staging was performed according to International Federation of Gynecology and Obstetrics (FIGO) 2009 [16]. The criteria recommended in National Comprehensive Cancer Network (NCCN) 2017 vulvar cancer guidelines were used for adjuvant treatment. [4]. Performance status and risk factors for recurrence were the factors affecting adjuvant treatment decision. Adjuvant RT was administered 6 weeks after surgery. Adjuvant CRT regime was addition of $40 \mathrm{mg} / \mathrm{m}^{2} \mathrm{cispl}-$ atin or 5-Fluorouracil to RT. The follow-up period was every 3 months for the first 2 years, every 6 months for the next 3 years and annual controls thereafter. Each follow-up visit included vulvovaginal and pelvic examination and imaging procedures in the suspicion of recurrence.

A total of 68 patients with vulvar squamous cell carcinoma (SCC) were enrolled in the study. The clinical and pathological features of the patients are shown in Table 1. The mean age was $64.7 \pm 10.9$ years. The most common $(37.6 \%)$ localization of the tumor was the right side of the vulva and $\leq 2 \mathrm{~cm}$ from the midline. The median tumor di- ameter was $2.8 \mathrm{~cm}(0.1-8.5)$. Most tumors were smaller than $4 \mathrm{~cm}$ (88.2\%). Tumor grade 1, 2 and 3 were found to be $50.0 \%, 47.1 \%$ and $2.9 \%$, respectively. LVSI was detected in $13.2 \%$ of the cases. Information on HPV status was available only in 25 patients. Surgical margin positivity was found to be in $11.8 \%$ of the patients. Sentinel lymphadenectomy was performed in $8.8 \%$ of the patients, and all nodes were non-metastatic. Twenty-three (33.8\%) patients had nodal

\section{Table 1. Clinical data of patients}

\begin{tabular}{|c|c|}
\hline & $n=68(\%)$ \\
\hline Age [years], mean $\pm S D$ & $64.7 \pm 10.9$ \\
\hline $\begin{array}{l}\text { Treatment } \\
\text { Only surgery } \\
\text { Surgery+RT/RCT }\end{array}$ & $\begin{array}{l}28(41.2) \\
40(58.8)\end{array}$ \\
\hline $\begin{array}{l}\text { Type of surgery } \\
\text { Radical vulvectomy } \\
\text { Simple vulvectomy } \\
\text { Wide local Excision }\end{array}$ & $\begin{array}{l}55(80.9) \\
9(13.2) \\
4(5.9)\end{array}$ \\
\hline $\begin{array}{l}\text { IFN lymhadenectomy } \\
\text { Ipsilateral } \\
\text { Bilateral } \\
\text { Sentinel }\end{array}$ & $\begin{array}{l}7(10.3) \\
55(80.9) \\
6(8.8)\end{array}$ \\
\hline Dissected lymph node count, median [range] & 11 [8-32] \\
\hline $\begin{array}{l}\text { Tumor diameter, median [range], } \mathrm{cm} \\
\qquad 4 \mathrm{~cm} \\
>4 \mathrm{~cm}\end{array}$ & $\begin{array}{l}2.8[0.1-8.5] \\
\quad 60(88.2) \\
\quad 8(11.8)\end{array}$ \\
\hline $\begin{array}{l}\text { Surgical margin } \\
\text { Positive } \\
\text { Negative }\end{array}$ & $\begin{array}{l}8(11.8) \\
60(88.2)\end{array}$ \\
\hline $\begin{array}{l}\text { Grade } \\
1 \\
2 \\
3\end{array}$ & $\begin{array}{l}34(50.0) \\
32(47.1) \\
2(2.9)\end{array}$ \\
\hline LVSI & $9(13.2)$ \\
\hline \begin{tabular}{c} 
Stage \\
I \\
IA \\
II \\
III \\
\multicolumn{2}{|l|}{ IIIA } \\
IIIB \\
IIIC \\
IVA \\
IVB
\end{tabular} & $\begin{array}{c}45(66.2) \\
4(5.9) \\
41(60.3) \\
0(0) \\
21(30.9) \\
11(16.2) \\
3(4.4) \\
7(10.3) \\
2(3.0) \\
1(1.5) \\
1(1.5)\end{array}$ \\
\hline Lymph node metastasis & $23(33.8)$ \\
\hline $\begin{array}{l}\text { Recurrence } \\
\text { Local } \\
\text { Groin recurrence } \\
\text { Distant Metastasis }\end{array}$ & $\begin{array}{l}18(26.5) \\
\quad 11(61.1) \\
4(22.2) \\
3(16.7)\end{array}$ \\
\hline $\begin{array}{l}\text { Adjuvant treatment } \\
\text { None } \\
\text { RT } \\
\text { CRT }\end{array}$ & $\begin{array}{l}28(41.2) \\
23(33.8) \\
17(25)\end{array}$ \\
\hline
\end{tabular}

SD — standard deviation; RT — Radiotherapy; CRT — Chemoradiotherapy; IFN — Inguinofemoral; LVSI — lymphovascular space invasion 
metastasis. The most frequent (60.3\%) stage was Stage IB. While 28 (41.2\%) patients undergoing primary surgery did not receive adjuvant therapy, 23 (33.8\%) were treated with adjuvant RT and 17 (25\%) with CRT. The median follow-up time was 28.5 (4-183) months. Recurrence occurred in 18 cases $(26.5 \%)$. The most common $(61.1 \%)$ recurrence site was local recurrence in the surgical field. Three (16.7\%) patients had distant recurrences, and the remaining (22.2\%) had recurrences in inguinofemoral lymph nodes. Secondary surgery was performed in $33.3 \%$ of all recurrent patients.

The institutional ethics committee approval was received for the study. SPSS software Ver.22 (SPSS Inc. Chicago, USA) was used for statistical analysis. Independent sample t-test, Mann Whitney U-test and Chi-squared test were used to determine the differences between the groups. Log-rank test was used to compare the factors affecting survival. Kaplan-Meier method was performed to estimate the OS and DFS. Cox univariate and multivariate regression analysis were performed to detect the prognostic factors for survival. $p<0.05$ was considered as statistically significant.

\section{RESULTS}

The 5 -year OS rate was $62.2 \%$, and the 5 -year DFS rate was $59.6 \%$. The mean OS of the group with lymph node metastasis ( 23 patients) was 67.0 months, while the mean OS of the non-metastatic group (45 patients) was 115.4 months $(p=0.028)$. OS was significantly higher in patients without lymph node metastasis. OS and DFS analyses for lymph node status are shown in Figures 1 and 2. The mean OS for the surgical margin-negative (60 patients) and positive (8 patients) patients were 107.9 months and 17.2 months, respectively $(p=0.003)$.

The clinicopathological features of the patients according to lymph node status are shown in Table 2. When those with and without lymph node metastasis were compared, there was no significant difference in terms of age, tumor localization, grade, number of dissected lymph nodes and recurrence. Tumor diameter was higher in the metastatic group ( $p=0.01$ ). LVSI and adjuvant treatment were more common in node-positive patients $(p=0.05, p<0.01$, respectively).

OS and DFS analyses of the patients are shown in Table 3. Age, surgical margin and lymph node metastasis were detected as significant prognostic factors for OS in univariate analysis ( $p=0.011, p=0.001, p=0.039$, respectively). In multivariate analysis, age and surgical margin positivity were important independent prognostic factors for OS [OR 1.07, $95 \% \mathrm{Cl}(1.01-1.12) \mathrm{p}=0.015 ;$ OR 4.76, $95 \% \mathrm{Cl}$ (1.46-15.53) $\mathrm{p}=0.010$, respectively]. Tumor diameter, lymph node metastasis and adjuvant treatment had no effect on OS in the multivariate analysis. Surgical margin positivity was a significant prognostic factor for DFS in univariate analysis

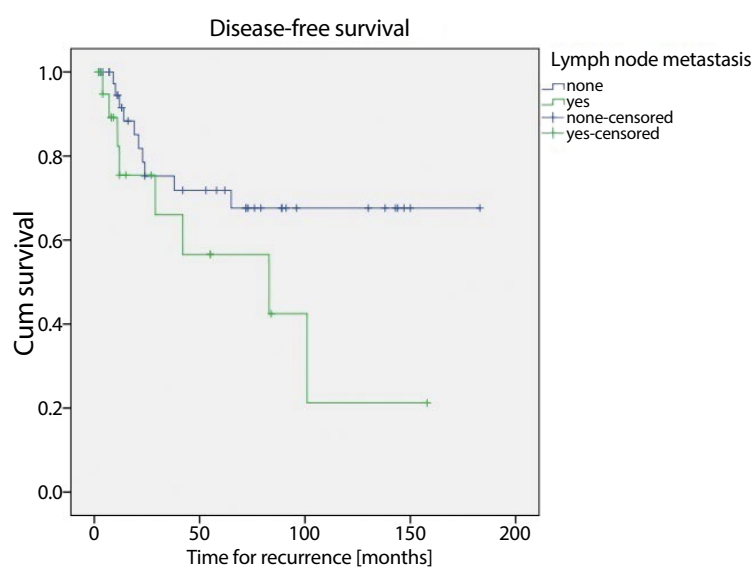

Figure 1. Disease-Free Survival for Lymph Node Status $(p=0.079)$

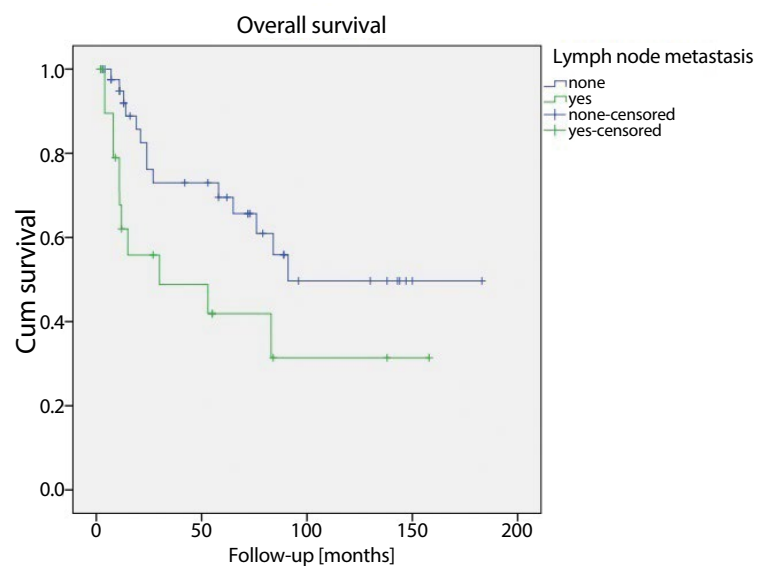

Figure 2. Overall survival for lymph node status $(p=0.028)$

[OR 2.81, 95\% Cl (0.59-13.2) p=0.020]. Age, tumor diameter, surgical margin, lymph node status and adjuvant treatment had no effect on DFS in multivariate analysis.

\section{Discussion}

Vulvar cancer is a rare tumor with prognostic factors described according to retrospective studies [6, 17-19]. The main limitation of these studies were heterogeneous study groups. The current study showed the experience of a tertiary center that had 20-years of experience in gynecologic oncology. The prognostic factors for OS and DFS were investigated in vulvar cancer patients with regular follow-up data. Lymph node metastasis had no effect on DFS. OS was higher in patients without lymph node metastasis. The distance to surgical margin lower than $8 \mathrm{~mm}$ was found to be an independent prognostic factor for OS.

Vulvar cancer is commonly seen in the elderly population. The age of diagnosis was reported to be 68 years [20]. Vulvar cancer was reported to occur in younger ages as 


\begin{tabular}{|c|c|c|c|}
\hline & LN metastasis, $\mathbf{n}=\mathbf{2 3}$ & No LN metastasis, $n=45$ & \\
\hline $\begin{array}{l}\text { Age, mean } \pm \text { SD [years], } n(\%) \\
\quad<65 \\
\quad \geq 65\end{array}$ & $\begin{array}{l}65.7 \pm 9.7 \\
13(56.5) \\
10(43.5)\end{array}$ & $\begin{array}{l}64.2 \pm 11.6 \\
21(53.3) \\
24(46.7)\end{array}$ & $\begin{array}{l}p=0.60^{a} \\
p=0.80^{c}\end{array}$ \\
\hline $\begin{array}{l}\text { Tumor diameter, median [range], } \mathrm{cm} \\
\qquad 4 \mathrm{~cm} \\
>4 \mathrm{~cm}\end{array}$ & $\begin{array}{l}3.2[0.3-6.5] \\
20(87.0) \\
3(13.0)\end{array}$ & $\begin{array}{l}2.6[0.1-8.5)] \\
40(88.9) \\
5(11.1)\end{array}$ & $\begin{array}{l}\mathbf{p}=\mathbf{0 . 0 1} \mathbf{1}^{\mathbf{b}} \\
p=1.00^{f}\end{array}$ \\
\hline $\begin{array}{l}\text { Tumor localisation, } \mathrm{n}(\%) \\
\text { Away from midline } \\
\text { Midline }\end{array}$ & $\begin{array}{l}3(13.0) \\
20(87.0)\end{array}$ & $\begin{array}{l}5(11.1) \\
40(88.9)\end{array}$ & $p=1.00^{f}$ \\
\hline $\begin{array}{l}\text { Grade, n (\%) } \\
\qquad \text { II-III }\end{array}$ & $\begin{array}{l}10(43.5) \\
13(56.5)\end{array}$ & $\begin{array}{l}24(53.3) \\
21(43.7)\end{array}$ & $p=0.44^{c}$ \\
\hline LVSI, n (\%) & $6(26.1)$ & $3(6.7)$ & $p=0.05^{f}$ \\
\hline Dissected lymph node count, median [range] & $10[8-30]$ & $12[8-32]$ & $p=0.48^{b}$ \\
\hline Positive surgical margin, $\mathrm{n}(\%)$ & $4(17.4)$ & $2(5.1)$ & $p=0.43^{f}$ \\
\hline Adjuvant treatment, n (\%) & $22(95.7)$ & $18(40.0)$ & $p<0.01^{c}$ \\
\hline Recurrence, n (\%) & $8(34.8)$ & $10(22.2)$ & $p=0.27^{c}$ \\
\hline
\end{tabular}

a — independent sample t-test; $\mathrm{b}$ — Mann-Whitney U-test; c — Chi-Square test; $\mathrm{f}$ — Fischer's exact test; SD — standard deviation; LVSI — lymphovascular space invasion; LN - lymph node; bold $p$ values are $<0.05$ and statistically significant

\begin{tabular}{|c|c|c|c|c|c|c|c|c|}
\hline & \multicolumn{4}{|l|}{ Overall survival } & \multicolumn{4}{|c|}{ Disease free survival } \\
\hline & \multicolumn{2}{|l|}{ Univariate analysis } & \multicolumn{2}{|c|}{ Multivariate analysis } & \multicolumn{2}{|c|}{ Univariate analysis } & \multicolumn{2}{|c|}{ Multivariate analysis } \\
\hline & OR $(95 \% \mathrm{Cl})$ & $\mathbf{P}$ & OR $(95 \% \mathrm{Cl})$ & $\mathbf{P}$ & OR $(95 \% \mathrm{Cl})$ & $\mathbf{P}$ & OR $(95 \% \mathrm{Cl})$ & $\mathbf{P}$ \\
\hline Age & $1.06(1.01-1.11)$ & 0.011 & $1.07(1.01-1.12)$ & 0.015 & $1.04(0.98-1.09)$ & 0.330 & $1.0(0.99-1.11)$ & 0.090 \\
\hline Tumor diameter & $1.26(1.00-1.59)$ & 0.053 & $1.04(0.75-1.44)$ & 0.826 & $1.15(0.85-1.54)$ & 0.070 & $1.04(0.70-1.53)$ & 0.840 \\
\hline $\begin{array}{l}\text { Surgical margin } \\
\text { Negative } \\
\text { Positive }\end{array}$ & $\begin{array}{l}\text { Reference } \\
5.30(2.04-13.76)\end{array}$ & 0.001 & $\begin{array}{l}\text { Reference } \\
4.76(1.46-15.53)\end{array}$ & 0.010 & $\begin{array}{l}\text { Reference } \\
2.81(0.59-13.2)\end{array}$ & 0.020 & $\begin{array}{l}\text { Reference } \\
1.80(0.35-9.20)\end{array}$ & 0.470 \\
\hline $\begin{array}{l}\text { LN metastasis } \\
\text { None } \\
\text { Yes }\end{array}$ & $\begin{array}{l}\text { Reference } \\
2.31(1.34-5.11)\end{array}$ & 0.039 & $2.54(0.94-6.86)$ & 0.067 & $\begin{array}{l}\text { Reference } \\
1.97(0.75-5.20)\end{array}$ & 0.460 & $\begin{array}{l}\text { Reference } \\
1.54(0.48-4.93)\end{array}$ & 0.460 \\
\hline $\begin{array}{l}\text { Adjuvant treatment } \\
\text { None } \\
\text { Yes }\end{array}$ & $\begin{array}{l}\text { Reference } \\
2.14(0.92-4.99)\end{array}$ & 0.077 & $\begin{array}{l}\text { Reference } \\
0.83(0.23-3.00)\end{array}$ & 0.772 & $\begin{array}{l}\text { Reference } \\
2.31(0.81-6.60)\end{array}$ & 0.420 & $\begin{array}{l}\text { Reference } \\
1.84(0.46-7.25)\end{array}$ & 0.380 \\
\hline
\end{tabular}

$\mathrm{OR}$ - odds ratio; $\mathrm{Cl}$ - confidence interval, Cox regression analyses; $\mathrm{LN}$ - lymph node; Bold $\mathrm{p}$ values are $<0.05$ and statistically significant

a result of an increase in HPV infection [21,22]. In accordance with these studies, the mean age of the patients at time of diagnosis was lower in our study.

Surgery is recommended both for staging and optimal treatment in vulvar cancer patients [2]. However, elder patients with medical comorbidities who cannot undergo surgery or those with advanced disease (in whom it is thought that the tumor will not be dissected with negative surgical margins) are managed with RT or CRT [2]. The management of vulvar cancer should be individualized by multidisciplinary teamwork $[3,4]$. Consistent with the recommendations, the patients in our study were discussed in a multidisciplinary tumor board, and most underwent surgery, while patients with advanced disease and medical comorbidities were treated with primarily RT or CRT. The most conservative individualized treatment was recommended to reduce morbidity and increase chance of cure [3]. Modified radical vulvectomy was performed in most patients in our study. Ipsilateral lymph node dissection was the recommended treatment of choice in patients with tumors $<4 \mathrm{~cm}$ in diameter and $\geq 2 \mathrm{~cm}$ from midline [4]. Since most of the tumors were located at $<2 \mathrm{~cm}$ from midline, bilateral lymphadenectomy was performed in most patients in the current study. Close surgical margins were reported to be an important risk factor for local recurrence [14]. Surgical removal of the tumors with negative margins at least $1 \mathrm{~cm}$ far from surgi- 
cal margins was recommended. [3]. Since negative surgical margin was achieved in most patients, the recurrence rate was consistent with the literature. Most women diagnosed with vulvar cancer are detected in the early stages of the diseases, as we found [6].

Local recurrence rate was reported up to $40 \%$ in previous studies [12]. Heterogeneous study groups in the studies were reported to be possible cause of different recurrence rates [14]. Maggino et al. [23] reported a recurrence rate of $37 \%$ in surgically treated vulvar cancer patients. On the other hand, a recurrence rate as low as 19\% was reported by Sznurkowski et al. [6]. Our recurrence rate was consistent with the literature. This may be due to the difference of the study designs or different age groups and adjuvant treatment regimens. Meelapkij et al. [24] examined 145 patients with vulvar SCC and detected 5 -year survival rate as $50.8 \%$. Although the study population was elder in our study, the 5 -year survival rate was found to be higher. Adjuvant treatment is recommended in patients with high-risk for recurrence $[3,4]$. However, the benefit of adjuvant treatment is not clear for the early stages of the disease. In the present study, lymph node positivity, margin positivity or tumor diameter greater than $4 \mathrm{~cm}$ were the criteria for administration of adjuvant treatment as recommended in NCCN guidelines [4]. Thus, by evaluating the patient's performance status, additional treatments were individualized, and the patients were treated with adjuvant RT or CRT by obtaining their informed contents.

Because of the rarity of vulvar cancer, the prognostic factors were evaluated by retrospective studies $[6,25]$. Raspaglisei et al. [25] reported that the most significant prognostic factor was the nodal status. 5-year survival for patients with negative nodes ranged from $70 \%$ to $93 \%$, and 5 -year survival for patients with positive nodes ranged from $25 \%$ to $41 \%$ [26]. Similar with the literature, OS for patients with metastatic nodes were lower in our study. However, the effect of lymph node metastasis on recurrence is conflicting [14]. Sznurkowski et al. [9] found that recurrence was more frequent in patients with negative lymph nodes. Conversely, Grootenhuis et al. [12] reported that patients with positive lymph nodes had a higher risk for local recurrence. In our study, there was no significant difference between the node-positive and node-negative groups in terms of recurrence. This result is thought to be related to the fact that most of the metastatic patients received adjuvant therapy. In addition, it was previously reported that adjuvant radiotherapy could lead to a lower risk of recurrence, which supports this idea [14]. Gadduci et al. [13] reported higher local recurrence for node-negative patients, but 2-years overall survival rate was very low (38\%), so the follow-up time was shorter for metastatic patients in their study.

In a prospective study, age was detected as a covariate associated with survival, and younger and older patients were recommended to be equally treated [27]. In our study, age was a significant prognostic factor for OS. Furthermore, tumor diameter was not an independent prognostic factor for OS [25]. Also, it was reported that tumor diameter had no effect on risk of local recurrence [14]. In convenient with the literature, tumor diameter had no effect on DFS and OS in our study. Most recurrences occur in the surgical field, so surgical margin status is an important factor in vulvar cancer [2]. The tumor is recommended to be dissected with at least $1 \mathrm{~cm}$ margin in NCCN and ESGO guidelines [3, 4]. In addition, previous studies have been carried out on whether close surgical margin increases risk of local recurrence or not [14, 15]. In a multicenter European study, 289 surgically treated node-negative patients were examined, and margin distance had no effect on local recurrence [15]. However, a histologic margin of $8 \mathrm{~mm}$ or less was detected as a risk factor for local recurrence in several studies $[9,28]$. In our study, positive surgical margin was an important prognostic factor for OS, but it was not significant for DFS.

The limitation of our study was its retrospective design. However, the number of patients studied was one of the highest single-center figures in the literature reported in our country. In addition, all patients were cared for in a tertiary cancer center with regular follow-up.

\section{CONCLUSIONS}

Our results showed that age and surgical margin positivity were independent prognostic factors for OS. Lymph node metastasis increased the hazard of death; however, it was not a predictor for OS. Although surgical margin positivity increased the risk of recurrence in univariate analysis, it was not a significant factor affecting DFS. OS was significantly lower in patients with lymph node metastasis.

\section{REFERENCES}

1. Banas T, Pitynski K, Jach R, et al. Primary Vulvo-Vaginal Cancers: Trends in Incidence and Mortality in Poland (1999-2012). Gynecol Obstet Invest. 2015; 80(4): 240-245, doi: 10.1159/000381770, indexed in Pubmed: 26065364.

2. Rogers LJ, Cuello MA. Cancer of the vulva. Int J Gynaecol Obstet 2018; 143 Suppl 2: 4-13, doi: 10.1002/ijgo.12609, indexed in Pubmed: 30306583.

3. Oonk MHM, Planchamp F, Baldwin P, et al. European Society of Gynaecological Oncology Guidelines for the Management of Patients With Vulvar Cancer. Int J Gynecol Cancer. 2017; 27(4): 832-837, doi: 10.1097/IGC.0000000000000975, indexed in Pubmed: 28441255.

4. Koh WJ, Greer BE, Abu-Rustum NR, et al. Vulvar Cancer, Version 1.2017, NCCN Clinical Practice Guidelines in Oncology. J Natl Compr Canc Netw. 2017; 15(1): 92-120, doi: 10.6004/jnccn.2017.0008, indexed in Pubmed: 28040721.

5. Mahner S, Jueckstock J, Hilpert F, et al. AGO-CaRE 1 investigators. Adjuvant therapy in lymph node-positive vulvar cancer: the AGO-CaRE-1 study. J NatI Cancer Inst. 2015; 107(3), doi: 10.1093/jnci/dju426, indexed in Pubmed: 25618900.

6. Sznurkowski JJ, Milczek T, Emerich J. Prognostic factors and a value of 2009 FIGO staging system in vulvar cancer. Arch Gynecol Obstet. 2013; 287(6): 1211-1218, doi: 10.1007/s00404-012-2683-x, indexed in Pubmed: 23263173.

7. van der Steen S, de Nieuwenhof HP, Massuger L, et al. New FIGO staging system of vulvar cancer indeed provides a better reflection 
of prognosis. Gynecol Oncol. 2010; 119(3): 520-525, doi: 10.1016/j. ygyno.2010.08.036, indexed in Pubmed: 20875914.

8. Zhou J, Shan G. The prognostic role of FIGO stage in patients with vulvar cancer: a systematic review and meta-analysis. Curr Med Res Opin. 2016; 32(6): 1121-1130, doi: 10.1185/03007995.2016.1162147, indexed in Pubmed: 26959073.

9. Sznurkowski JJ, Emerich J. Characteristic features of recurrences of squamous cell carcinoma of the vulva. Ginekol Pol. 2010; 81(1): 12-19, indexed in Pubmed: 20232693.

10. Heaps JM, Fu YS, Montz FJ, et al. Surgical-pathologic variables predictive of local recurrence in squamous cell carcinoma of the vulva. Gynecol Oncol. 1990; 38(3): 309-314, doi: 10.1016/0090-8258(90)90064-r, indexed in Pubmed: 2227541.

11. Nooij LS, van der Slot MA, Dekkers OM, et al. Tumour-free margins in vulvar squamous cell carcinoma: Does distance really matter? Eur J Cancer. 2016; 65: 139-149, doi: 10.1016/j.ejca.2016.07.006, indexed in Pubmed: 27497345.

12. Te Grootenhuis NC, van der Zee AGJ, van Doorn HC, et al. Sentinel nodes in vulvar cancer: Long-term follow-up of the GROningen INternational Study on Sentinel nodes in Vulvar cancer (GROINSS-V) I. Gynecol Oncol. 2016; 140(1): 8-14, doi: 10.1016/j.ygyno.2015.09.077, indexed in Pubmed: 26428940.

13. Gadducci A, Ferrero A, Tana $R$, et al. Prognostic value of lymph node status and number of removed nodes in patients with squamous cell carcinoma of the vulva treated with modified radical vulvectomy and inguinal-femoral lymphadenectomy. Eur J Gynaecol Oncol. 2012; 33(6): 640-643, indexed in Pubmed: 23327062

14. Te Grootenhuis NC, Pouwer AFW, de Bock GH, et al. Prognostic factors for local recurrence of squamous cell carcinoma of the vulva: A systematic review. Gynecol Oncol. 2018; 148(3): 622-631, doi: 10.1016/j. ygyno.2017.11.006, indexed in Pubmed: 29137809.

15. Woelber L, Griebel LF, Eulenburg C, et al. Role of tumour-free margin distance for loco-regional control in vulvar cancer-a subset analysis of the Arbeitsgemeinschaft Gynäkologische Onkologie CaRE-1 multicenter study. Eur J Cancer. 2016; 69: 180-188, doi: 10.1016/j.ejca.2016.09.038, indexed in Pubmed: 27837710.

16. Hacker NF. Revised FIGO staging for carcinoma of the vulva. Int J Gynaecol Obstet. 2009; 105(2): 105-106, doi: 10.1016/j.ijgo.2009.02.011, indexed in Pubmed: 19329116.

17. Woelber L, Eulenburg C, Choschzick M, et al. Prognostic role of lymph node metastases in vulvar cancer and implications for adjuvant treatment. Int J Gynecol Cancer. 2012; 22(3): 503-508, doi: 10.1097/IGC.0b013e31823eed4c, indexed in Pubmed: 22266935.
18. Cheng $\mathrm{Xi}$, Zang $\mathrm{R}, \mathrm{Wu} \mathrm{X}$, et al. Recurrence patterns and prognostic factors in Chinese patients with squamous cell carcinoma of the vulva treated with primary surgery. Int J Gynecol Cancer. 2009; 19(1): 158-162, doi: 10.1111/IGC.0b013e3181996a78, indexed in Pubmed: 19258959.

19. Nicoletto MO, Parenti A, Del Bianco $P$, et al. Vulvar cancer: prognostic factors. Anticancer Res. 2010; 30(6): 2311-2317, indexed in Pubmed: 20651385.

20. Akhtar-Danesh N, Elit L, Lytwyn A, et al. Trends in incidence and survival of women with invasive vulvar cancer in the United States and Canada: a population-based study. Gynecol Oncol. 2014; 134(2): 314-318, doi: 10.1016/j.ygyno.2014.05.014, indexed in Pubmed: 24875124.

21. Barlow EL, Kang YJ, Hacker NF, et al. Changing Trends in Vulvar Cancer Incidence and Mortality Rates in Australia Since 1982. Int J Gynecol Cancer. 2015; 25(9): 1683-1689, doi: 10.1097/IGC.0000000000000547, indexed in Pubmed: 26495761.

22. Kang YJ, Smith M, Barlow E, et al. Vulvar cancer in high-income countries: Increasing burden of disease. Int J Cancer. 2017; 141(11): 2174-2186, doi: 10.1002/ijc.30900, indexed in Pubmed: 28730615.

23. Maggino T, Landoni F, Sartori E, et al. Patterns of recurrence in patients with squamous cell carcinoma of the vulva. A multicenter CTF Study. Cancer. 2000;89(1):116-122, doi: 10.1002/1097-0142(20000701)89:1<116::ai d-cncr16>3.0.co;2-4, indexed in Pubmed: 10897008.

24. Meelapkij P, Suprasert $P$, Baisai O. Treatment Outcomes of Patients with Squamous Cell Carcinoma of the Vulva: The Largest Series from a Tertiary Care Hospital. Obstet Gynecol Int. 2018; 2018: 4723167, doi: 10.1155/2018/4723167, indexed in Pubmed: 30250487.

25. Raspagliesi F, Hanozet F, Ditto A, et al. Clinical and pathological prognostic factors in squamous cell carcinoma of the vulva. Gynecol Oncol. 2006; 102(2): 333-337, doi: 10.1016/j.ygyno.2005.12.027, indexed in Pubmed: 16466657.

26. Gadducci A, Cionini L, Romanini A, et al. Old and new perspectives in the management of high-risk, locally advanced or recurrent, and metastatic vulvar cancer. Crit Rev Oncol Hematol. 2006; 60(3): 227-241, doi: 10.1016/j.critrevonc.2006.06.009, indexed in Pubmed: 16945551.

27. Panici PB, Tomao F, Domenici L, et al. Prognostic role of inguinal lymphadenectomy in vulvar squamous carcinoma: younger and older patients should be equally treated. A prospective study and literature review. Gynecol Oncol. 2015; 137(3):373-379, doi: 10.1016/j.ygyno.2015.03.013, indexed in Pubmed: 25887098.

28. Yap J, O'Neill D, Nagenthiran S, et al. Current insights into the aetiology, pathobiology, and management of local disease recurrence in squamous cell carcinoma of the vulva. BJOG. $2017 ; 124(6)$ : 946-954, doi: 10.1111/1471-0528.14560, indexed in Pubmed: 28081287. 